ISSN 1816-6075 (Print), 1818-0523 (Online)

Journal of System and Management Sciences

Vol. 9 (2019) No. 3, pp. 45-64

DOI:10.33168/JSMS.2019.0303

\title{
Algorithm of Three-Party Combined Judgment Analysis Engine for Earthquake Early Warning System
}

\author{
Youn Soo Park ${ }^{1}$ and Jeong Hun Choi ${ }^{2 *}$ \\ ${ }^{1}$ Department of Information and Communication Engineering, Korea Polytechnic \\ University, Republic of Korea \\ 2* (Professor, Corresponding Author) 15119 Dept. of Electronic Engineering, Korea \\ Polytechnic Univ., Jungwang-dong Siheung-City, Gyeonggi-Do, Korea \\ ${ }^{1}$ davepark@kpu.ac.kr, ${ }^{2} j h c h o i @ k p u . a c . k r$
}

\begin{abstract}
Thus far, it has been impossible to predict earthquakes accurately, and the best approach so far provides earthquake early warnings by analyzing earthquake information and disseminating warnings rapidly. Earthquake early warning systems (EEWS) must be able to observe P waves (tremors) that spread at a relatively rapid rate, preemptively warn of the risk of damage from the $S$ waves that will subsequently arrive, and prompt residents to evacuate immediately. South Korea's current EEWS can issue earthquake warnings within $25 \mathrm{~s}$ of observing the first $\mathrm{P}$ wave. For earthquakes occurring inside the observation network, the epicenter positional error is aimed at within $5 \mathrm{~km}$ and the magnitude error within $\pm 0.5 \mathrm{~km}$. For further development of the EEWS used in South Korea, it is first necessary to construct a more rapid, accurate, and stable system by employing scale formulas that determine the scale of the $\mathrm{P}$ wave earthquakes using domestic earthquake data. To this end, $\mathrm{P}$ wave observations must be performed within $5 \mathrm{~s}$ of the occurrence of the earthquake. Existing EEWSs usually use a one-party combined judgment method to predict earthquakes. A seismograph is installed only at one location within a building, and this can lead to judgment errors. In the future, it will be necessary to minimize judgment errors through the stabilization of the EEWS and to perform multi-faceted studies that allow rapid and accurate earthquake judgments to be made. To resolve these problems, this study proposes a new three-party combined judgment method which can determine whether an earthquake is occurring within
\end{abstract}


a maximum of $5 \mathrm{~s}$ after vibrations occur by selecting three major comparison patterns for earthquake detection, reprocessing dual sensors as triple sensors, and making sub-judgments and final judgments.

Keywords: three-party combined judgment, earthquake early warning system, internet of things, vector sum, MEMS sensor, $\mathrm{P}$ waves, golden time

\section{Introduction}

In particular, natural disasters occur the most in the Asian continent, and earthquakes cause the most damage The Center for Research on the Epidemiology of Disasters (CRED) reported that the deadliest incident of 2018 left 564 people dead or missing in an earthquake that left 4,340 people dead or injured in Indonesia. Worldwide, the 2018 earthquake killed 5,264 people, [Fig 1].

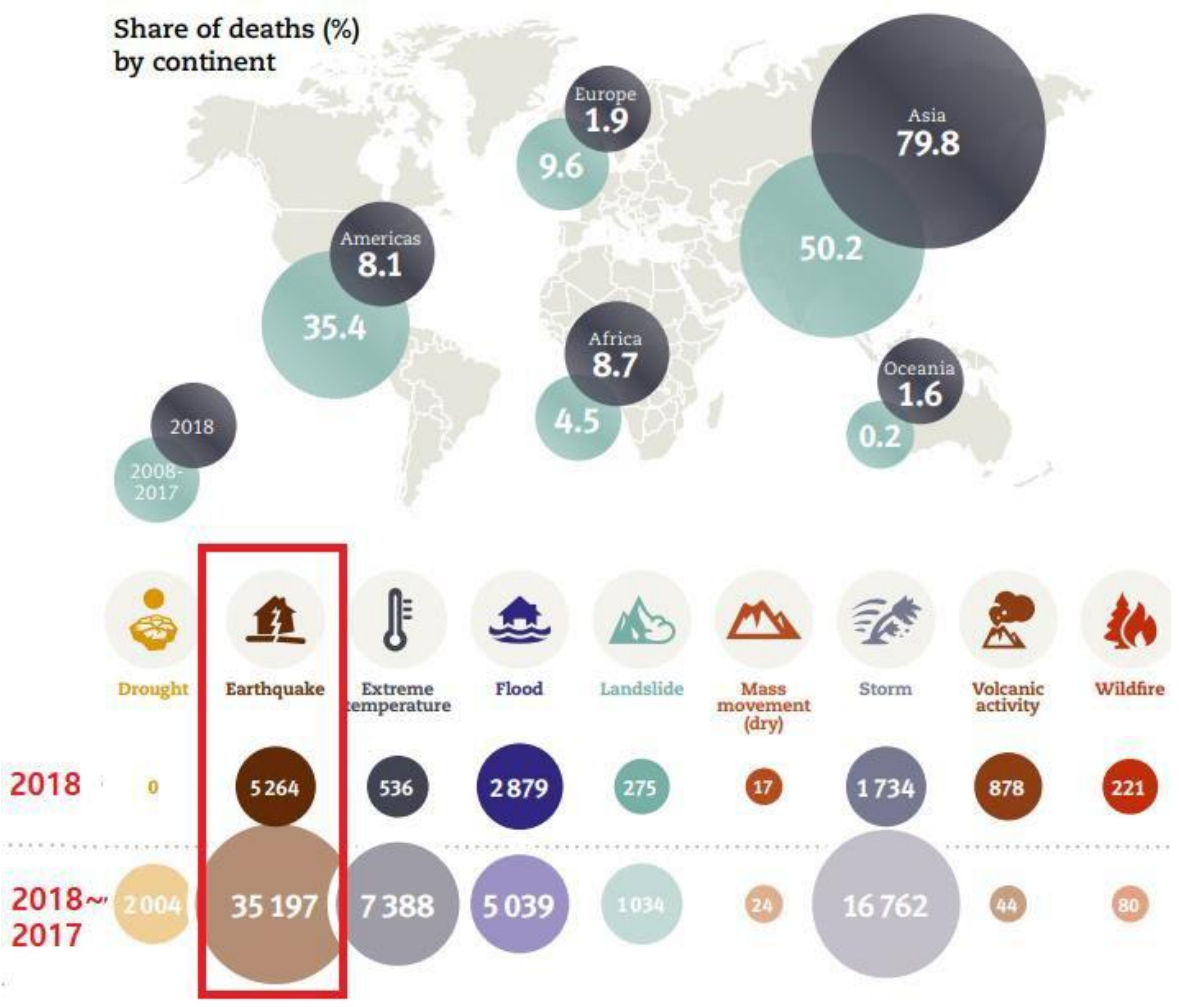

Fig. 1: Total deaths from an earthquake at 2017 2018

Up to now, because it is not possible to accurately predict earthquakes in advance, the best earthquake early warning method is to analyze earthquake information and rapidly disseminate warnings. It took about 120 years for the possibility and measures of early seismic alerts to become a reality after they were proposed by Dr. Cooper in 1868. The most important research issue on the current seismic alerts is securing "golden time," a limited time that can save people's lives. 
In general, the initial $\mathrm{P}$ waves observation should be made within $5 \mathrm{~s}$ to secure the gold time, the time limit for saving human breath, since the $S$ waves are detected 5 to $20 \mathrm{~s}$ after the $\mathrm{P}$ waves reached in the event of an earthquake.

Since the Korea Meteorological Administration began instrumental earthquake observations in 1978, the largest-scale earthquake was a magnitude 5.8 earthquake which occurred at the city of Gyeongju, Gyeongsangbuk-do on September 12, 2016. According to reports by the Ministry of Public Safety and Security, there were 23 injured persons and 5,210 instances of property damage. One week after the main shock, a magnitude 4.5 earthquake occurred, as well as over 400 aftershocks. On September 22, the government declared Gyeongju to be a special disaster area for the first time due to the earthquake damage.

Earthquake early warning system(EEWS) must be able to observe $\mathrm{P}$ waves (tremors) which spread at a relatively rapid rate, preemptively warn of the risk of damage from the $\mathrm{S}$ waves that will subsequently arrive, and prompt residents to evacuate immediately. South Korea's current EEWS is capable of issuing earthquake warnings within $25 \mathrm{~s}$ of observing the first $\mathrm{P}$ waves, and officials have pledged to reduce the earthquake warning issuance time to less than $10 \mathrm{~s}$ after observing P waves by 2020 (Nakamura et al., 2007).

For earthquakes occurring inside the observation network, the epicenter positional error is aimed at within $5 \mathrm{~km}$ and the magnitude error within $\pm 0.5 \mathrm{~km}$. For this purpose, dense stations with inter-station intervals of $22 \mathrm{~km}$ will be constructed [Fig. 2]. $\mathrm{P}$ waves can be observed at six stations within $5 \mathrm{~s}$ if an earthquake occurs at $10 \mathrm{~km}$ below ground level (Sheen et al., 2012).

If the epicenter is located at the center of the triangle's observation network, the distance from the epicenter to the station is the furthest at about $16 \mathrm{~km}$, and a $\mathrm{P}$ wave is detected at the station about $2.7 \mathrm{~s}$ after the earthquake. If the magnitude is estimated from $\mathrm{P}$ wave data for $1 \mathrm{~s}$, an alert may be issued at the site prior to the arrival of the $S$ waves [Fig. 3].

To do this, $\mathrm{P}$ wave observations must be performed within $5 \mathrm{~s}$ of the earthquake occurring. Existing EEWSs usually use a one-party combined judgment method to make earthquake judgments. Normally, a seismograph is installed at one location within a building, and judgment errors can occur (Yang et al., 2018).

In the case of the Gyeongju earthquake, a magnitude 5.1 foreshock was observed at 19:44:32 s on September 12, 2016, and a notification was issued $27 \mathrm{~s}$ later. $4 \mathrm{~min}$ and $28 \mathrm{~s}$ later at 19:49:00, an announcement was made. After the foreshock, the magnitude 5.8 main shock occurred at 20:32:54. It was observed $29 \mathrm{~s}$ later at 20:33:23, and an earthquake notification was issued at 20:37:00, which was $4 \mathrm{~min}$ and $6 \mathrm{~s}$ later. Afterward, there were cases in which continued earthquake messages were sent to users because of slight vibrations (Park et al., 2012). 


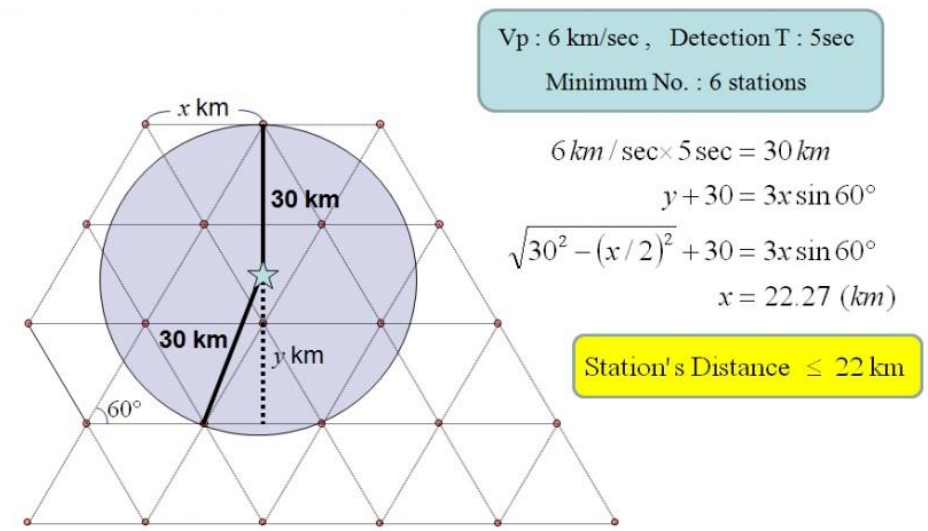

Fig. 2: Optimal station's distance for distribution of 6 stations within $30 \mathrm{~km}$ from an epicenter

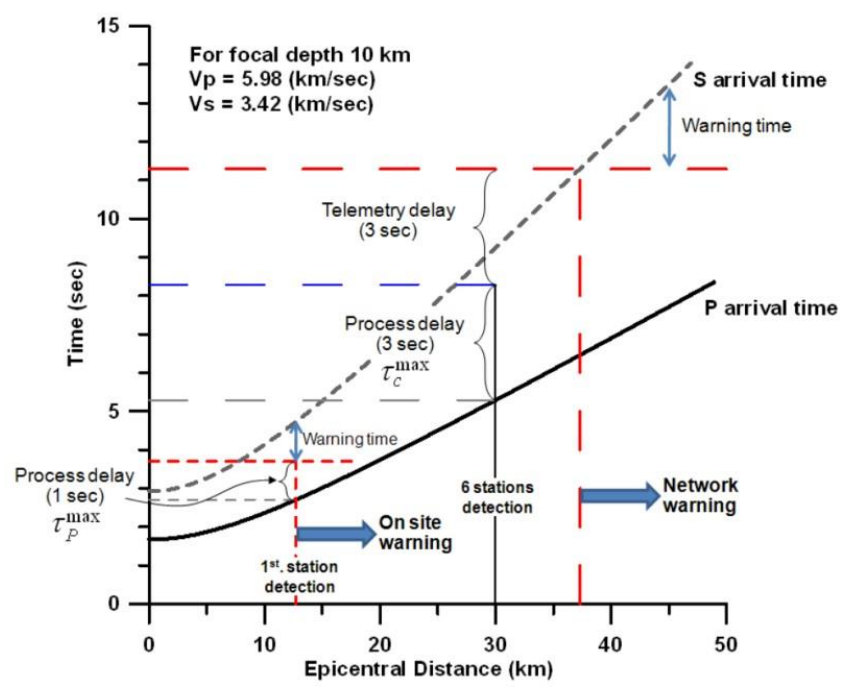

Fig. 3: Warning times depend on On site or Network warning method

In the future, it will be necessary to minimize judgment errors through stabilization of the EEWS and to perform multi-faceted studies that allow rapid and accurate earthquake judgments to be made.

To resolve these problems, this study proposes a new three-party combined judgment method which can determine whether an earthquake is occurring within a maximum of $5 \mathrm{~s}$ after vibrations occur by selecting three major comparison patterns for earthquake detection, reprocessing dual sensors as triple sensors, and making sub-judgments and final judgments.

The composition of this paper is as follows. First, Section 2 describes the threeparty combined judgment technology and configuration of the three-party combined judgment analysis engine. Section 3 describes the design of new algorithm for the 
three-party combined judgment and the composition of physical model. Numerical test results through implementation of the algorithm proposed in Section 4 are presented and conclusions are concluded in Section 5.

\section{Three-Party Combined Judgment Technology}

Existing EEWSs usually install seismometers in only one building, and use one-way combined judgment methods to determine earthquakes, which not only makes them less reliable, but can also lead to misjudgment.

As a three-party combined judgment technology that can address these low reliability and misjudgment problems, the 'three-party combined judgment analysis engine' is proposed.

\subsection{The three-party combined judgment approach}

The three-party combined judgment analysis engine performs multifaceted earthquake judgments through (1) an IoT sever which increases system efficiency, (2) earthquake analysis and a control processor, (3) earthquake control and a controller, and (4) IoT sensors. This approach finds pattern-based earthquake identification algorithms and minimizes important earthquake judgment errors that are relevant to ensuring golden time. The three-party combined judgment approach is a method for ensuring golden time.

\subsection{Function of three-party combined judgment analysis engine}

The three-party judgment analysis engine, which performs multifaceted judgments regarding normal vibrations and $\mathrm{P}$ waves, can provide advance warnings to management personnel and building residents when confirmed $\mathrm{P}$ waves occur and the vibrations are a risk to the building, or when a 4.0 magnitude on the modified Mercalli scale is confirmed.

It can also provide guides for building and neighborhood evacuation paths and neighborhood evacuation shelters in order to minimize the human harm that can occur when the main shock hits.

Also, before the occurrence of major risks such as $\mathrm{S}$ waves (main shocks) that cause a building to become dangerous, it can perform primary shutting off of gas valves either automatically or through an administration office control screen. And it can physically shut off major power equipment through a final judgment to reduce secondary physical damage.

The three-party judgment method performs a waveform analysis (directionality /acceleration) on the accelerometer-based vibration information provided by three or more fixed sensors that are spaced at a set distance in order to discern between normal vibrations and $\mathrm{P}$ wave vibrations. Then it compares the similarities between the occurrence data and the history of previous occurrences and makes a judgement that incorporates the earthquake judgment results from nearby buildings that were collected via IoT servers [Fig. 4]. 


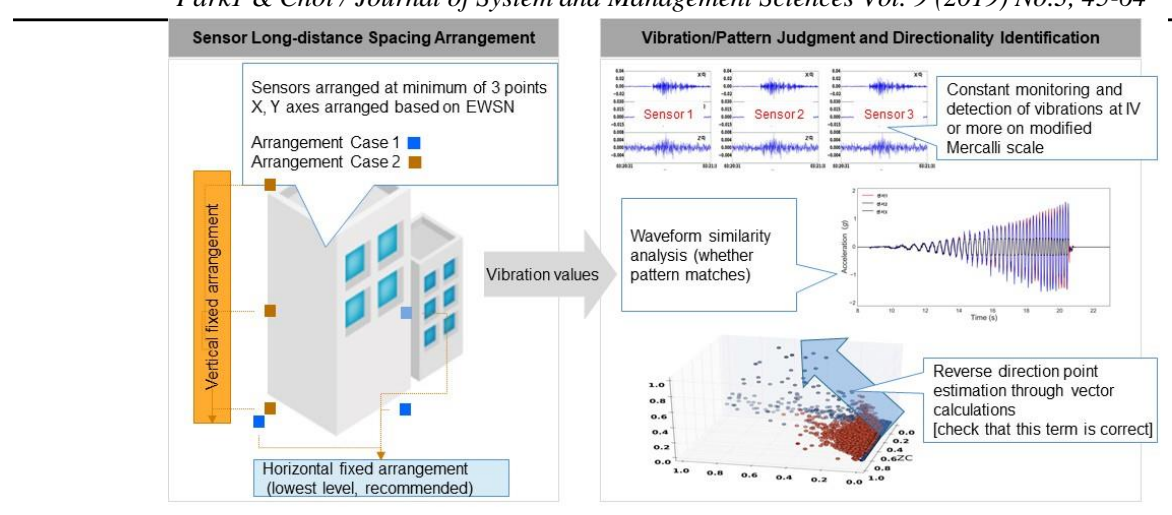

Fig. 4: Tripartite placement and consistency of the vibration device (sensor)

Finally, it performs confirmation processing regarding the earthquake. The primary standard for identifying earthquakes refers to the 3 seismic device (sensor) locations within the building, the nearby buildings, and the history information in order to make a final judgment [Fig. 5].
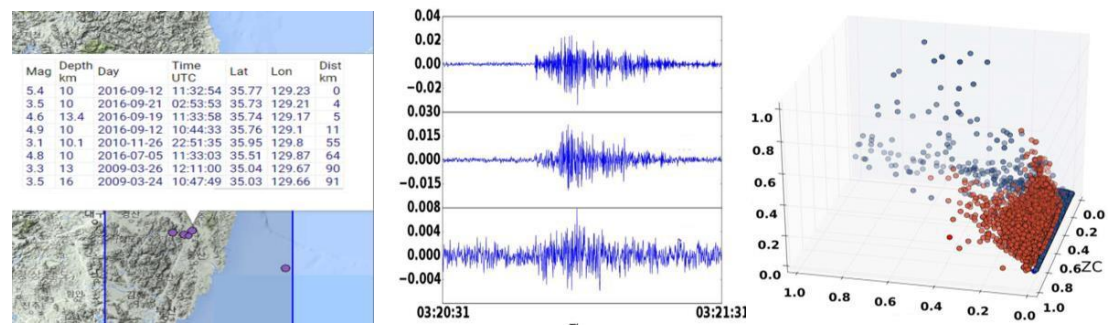

Fig. 5: Comparison between real-time data and existing data history

\section{Proposed Three-Party Combined Judgment Algorithm}

This section describes the pattern seismic identification algorithms that refine seismic determination methods by comparing data on three or more attenuation sensor devices with the vibration conditions, past history, and waveform analysis patterns of nearby buildings to determine risk and increase accuracy.

\subsection{The three-party combined judgment method}

The three-party combined judgment method is an integrated analysis method that compares actual measurement data and the previous history and uses information on nearby areas. It allows for rapid earthquake confirmation judgments and can prescribe follow-up measures.

First, the three-party three-axis sensor is installed at the lowest layer with at least 30 $\mathrm{m}$ of spacing. If there are more than 30 layers, the sensors are installed at the lowest layer, middle layer, and top layer. The system also updates and uses the history information on previous earthquake occurrences, including the epicenter, focus, scale, etc.

Second, patterning (diagramming) of the vectors (directionality and acceleration of gravity) for the vibrations received from the three or more sensors is performed 
during the data collection and abnormality filtering tasks. If a vibration larger than a IV on the modified Mercalli scale occurs, a judgment is requested from the earthquake identification module, and data on earthquake occurrences in nearby regions is requested and collected from IoT servers.

Third, sensor data judgments are performed in the earthquake identification module. If waveform patterns from 2 or more places are similar, it is classified as a significant target. If waveform patterns from 3 or more places are similar, it is reported as an earthquake occurrence. Also, the waveform similarity between the estimated epicenter (direction) and the earthquake occurrence history is compared based on vector values. The judgement results from nearby buildings, which were collected via IoT servers, are confirmed.
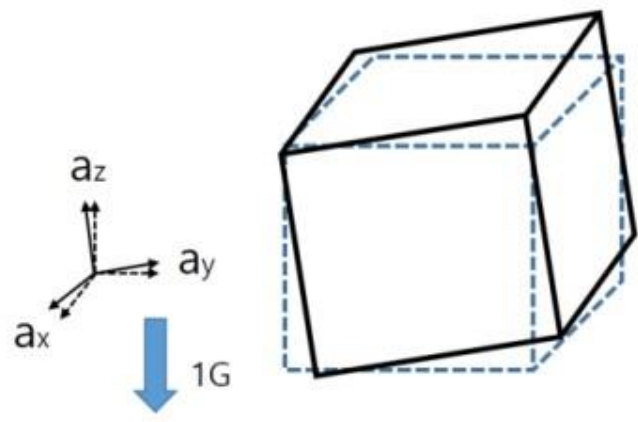

Fig. 6: The acceleration of gravity and vector sum

In the configuration which has usually been employed in the past, three-axis accelerometer sensors are installed, and if a sensor measurement diverges from the initial value by more than a fixed amount, the vibration is found to be caused by an earthquake. In Eq. (1) below, $\alpha x, \alpha y$, and $\alpha z$ are acceleration data measured in the three axis directions. $\alpha 0$ is the reference value, and $\Delta$ warn is the acceleration's allowed variability range. Here, $\alpha 0$ is $1 \mathrm{~g}$ or $0 \mathrm{~g}$ if the sensor module is precisely aligned along the building's $\mathrm{x}, \mathrm{y}$, and $\mathrm{z}$ axes.

$$
\alpha_{0}-\Delta_{w a r n}<a_{x}, \alpha_{y}, \alpha_{z}<\alpha_{0}+\Delta_{w a r n}
$$

However, this method has problems with increased installation costs because the range by which abnormal vibrations are judged must be adjusted multiple times because the normal output of individual sensors varies due to the slight changes in angles that occur each time sensor modules are installed. To solve this problem, it is possible to use the point where the vector sum of the 3 axes' individual accelerations in a state without external force is always the same as the terrestrial gravity acceleration of $1 \mathrm{~g}$. This point can be used to judge whether an earthquake is occurring by confirming whether the acceleration vector sum goes outside of a fixed range from $1 \mathrm{~g}$. Therefore, when installation is precise, the required cost problem can be avoided. When three individual three-axis accelerometers are used to perform a three-party combined judgment and two or more earthquake detections occur, it can be determined that an earthquake is occurring, and a rapid and accurate 
earthquake judgment can be made [Fig 6].

$$
\begin{aligned}
& 1_{g}-\Delta_{\text {warn }}<G_{\text {total }} \\
& =\sqrt{a^{2 x}+a^{2 y}+a^{2 z}}<1_{g}+\Delta_{\text {warn }}
\end{aligned}
$$

The output of the three-axis acceleration sensors is received sequentially at a high speed, and the sum of this output's vectors is calculated for each moment. The system checks whether this value diverges from the initially set warning level. If the actual input acceleration value for each axis is found, the acceleration's value can be found by subtracting the voltage offset from the sensor output voltage and dividing that value by the pre-measured sensor sensitivity value. If the sum of the acceleration vectors for the three axis directions is found, the measured vibration's $\mathrm{G}$ value can be confirmed because $1 \mathrm{~g}$ is always maintained in a state where here are no external forces. If its variation is outside of the preset range, it can be understood as being a $\mathrm{P}$ wave vibration signal (Lee et al., 2014).

$$
G_{\text {total }}=\sqrt{a^{2_{x}}+a^{2 y}+a^{2 x}}
$$

The three-party judgment method performs a waveform analysis (directionality /acceleration) on the accelerometer-based vibration information provided by three or more fixed sensors that are spaced at a set distance in order to discern between normal vibrations and $\mathrm{P}$ wave vibrations. Then it compares the similarities between the occurrence data and the history of previous occurrences and makes a judgement that incorporates the earthquake judgment results from nearby buildings that were collected via IoT servers. Finally, it performs confirmation processing regarding the

\begin{tabular}{|c|c|c|}
\hline Category & $\begin{array}{l}\text { Conventional One Party } \\
\text { Three-axis Judgment }\end{array}$ & $\begin{array}{c}\text { Three-Party Three-axis Combined } \\
\text { Judgment Method }\end{array}$ \\
\hline Faults & $\begin{array}{l}\text { If equipment (sensor) faults } \\
\text { occur, they cannot be detected }\end{array}$ & $\begin{array}{l}\text { If two or more of the three arranged } \\
\text { sensors are working normally, they can } \\
\text { be used to perform earthquake } \\
\text { judgments }\end{array}$ \\
\hline $\begin{array}{c}\text { Malfunctions / } \\
\text { Misidentificatio } \\
n\end{array}$ & $\begin{array}{l}\text { If the equipment (sensor) } \\
\text { malfunctions due to a } \\
\text { temporary reason and an } \\
\text { incorrect value is provided, } \\
\text { judgment errors can occur }\end{array}$ & $\begin{array}{l}\text { The allowed error range for sensor } \\
\text { measurement values is set, and a } \\
\text { determination is made regarding whether } \\
\text { all of the acceleration values measured } \\
\text { by the sensors within the range are valid. } \\
\text { Invalid values are not included in the } \\
\text { judgment }\end{array}$ \\
\hline Increase in the & Vibrations must be at a & The three sensors' directionality is \\
\hline
\end{tabular}
earthquake (Table 1).

Table 1: Method of arrangement of vibration apparatus 
Park1 \& Choi / Journal of System and Management Sciences Vol. 9 (2019) No.3, 45-64

\begin{tabular}{|c|c|c|}
\hline $\begin{array}{c}\text { lowest level for } \\
\text { earthquake } \\
\text { detection }\end{array}$ & $\begin{array}{l}\text { minimum of IV on the modified } \\
\text { Mercalli scale. However, there } \\
\text { are many cases in which the } \\
\text { detection standard is raised } \\
\text { because incorrect earthquake } \\
\text { detection can occur when } \\
\text { surface level construction is } \\
\text { performed on nearby buildings } \\
\text { due to the characteristics of the } \\
\text { equipment which is located at } \\
\text { only one place }\end{array}$ & $\begin{array}{l}\text { confirmed based on the } x, y, \text { and } z \text {-axis } \\
\text { accelerometer vector values, which are } \\
\text { the sensor measurement values. If the } \\
\text { vibration is occurring near the building, it } \\
\text { is classified as a normal vibration rather } \\
\text { than an earthquake. Even if it is a normal } \\
\text { vibration, it is identified as dangerous if it } \\
\text { is severe. }\end{array}$ \\
\hline
\end{tabular}

The three-party combined judgement determines the consistency of the three sensors by comparing their similarity to each other through pattern analysis and linear analysis methods. If the maximum peak value (positive number value) of the three sensors for a certain time interval is found to satisfy the basic judging criteria of the seismic equipment (Table II), the vibration is judged to be consistent.

Table II. Basic Judging Criteria For Vibration Devices

\begin{tabular}{l|l}
\hline \multicolumn{1}{c|}{ Judgment Conditions } & \multicolumn{1}{c}{ Determination } \\
\hline \hline $\begin{array}{l}\text { Sensor 1's significant vibration value (acceleration) }<= \\
\text { sensor, sensor } 3 \text { and 2's peak value is not within the } \pm \\
\text { error rate }\end{array}$ & $\begin{array}{l}\text { Vibration consistency of 1/3 } \\
\text { (i.e. only one judges it to be a } \\
\text { vibration) }\end{array}$ \\
\hline $\begin{array}{l}\text { Sensor 1's significant vibration value (acceleration) }<= \\
\text { sensor, sensor 2's peak value is within the } \pm \text { error rate } \\
\text { but sensor } 3 \text { is not }\end{array}$ & $\begin{array}{l}\text { Vibration consistency of 2/3 } \\
\text { (i.e. only two judge it to be a } \\
\text { vibration) }\end{array}$ \\
\hline $\begin{array}{l}\text { In the same manner as sensor 1, sensors 2 and 3 are } \\
\text { both in the error rate range }\end{array}$ & $\begin{array}{l}\text { Vibration consistency of 3/3 } \\
\text { (100\% confirmed to be an } \\
\text { earthquake or building risk) }\end{array}$ \\
\hline
\end{tabular}

To perform this process, the "sensor peak judgment error rate" value must be set by the earthquake control and controller software. Whether the values are within the error rate range is determined by the following formulas (Table III). The threshold value which distinguishes normal vibration values from $\mathrm{P}$ wave vibration values is set in the earthquake control and controller software.

Table III. Criteria for determining 'Sensor Peak Decision Fraction' of a Diagnostic Equipment

\begin{tabular}{l|l}
\hline \multicolumn{1}{c|}{ Judgment Conditions } & \multicolumn{1}{c}{ Determination } \\
\hline \hline $\begin{array}{l}\text { Sensor } 2 \text { maximum peak value/Sensor } 1 \text { maximum peak } \\
\text { value } * 100<=\text { error rate }\end{array}$ & Consistency increased by 1 \\
\hline
\end{tabular}




\begin{tabular}{l|l}
\hline $\begin{array}{l}\text { Sensor } 3 \text { maximum peak value/Sensor } 1 \text { maximum peak } \\
\text { value } * 100<=\text { error rate }\end{array}$ & Consistency increased by 1 \\
\hline Other cases & $\begin{array}{l}\text { According to basic vibration } \\
\text { consistency judgment criteria }\end{array}$ \\
\hline
\end{tabular}

* Vibration consistency is expressed in the form of the sum of each consistency value/the number of target sensors.

The judgment criteria for sensor acceleration vector values are set as follows [Table IV] and defined for future use in accordance with the characteristics of the area (such as the usual construction area).

Table IV. Judgment Criteria for Sensor Acceleration Vector Values

\begin{tabular}{c|c|l|l}
\hline ALIVE & $\begin{array}{c}\text { Vibration } \\
\text { Consistency }\end{array}$ & \multicolumn{1}{c}{$\begin{array}{c}\text { Status } \\
\text { Results }\end{array}$} & \multicolumn{1}{c}{ Judgment } \\
\hline \hline $3 / 3$ & $1 / 3$ & Normal & $\begin{array}{l}\text { Determination of some vibrations due to other } \\
\text { causes, not earthquake }\end{array}$ \\
\hline $3 / 3$ & $2 / 3$ & $\begin{array}{l}\text { Vibration } \\
\text { Sensing }\end{array}$ & $\begin{array}{l}\text { It is not an earthquake, but the equivalent shaking } \\
\text { is considered dangerous as it is detected in the } \\
\text { building. }\end{array}$ \\
\hline $2 / 3$ & $3 / 3$ & $\begin{array}{l}\text { Vibration } \\
\text { Sensing }\end{array}$ & $\begin{array}{l}\text { The current building is sure to have an } \\
\text { earthquake. } \\
\text { Announce an earthquake warning. } \\
\text { We need to alert neighboring buildings. }\end{array}$ \\
\hline $2 / 3$ & $1 / 3$ & Normal & $\begin{array}{l}\text { Determination of some vibrations due to other } \\
\text { causes, not earthquake. } \\
\text { Adjust the setting of the non-response sendor. }\end{array}$ \\
\hline $1 / 3$ & $1 / 3$ & $\begin{array}{l}\text { Vonsider it as an earthquake-determined } \\
\text { decision. } \\
\text { Announce an earthquake warning. } \\
\text { We need to alert neighboring buildings. }\end{array}$ \\
\hline
\end{tabular}

\subsection{Architecture of proposed algorithm}

The control server communicates the reference and external judgment information to the seismic detection IoT sensors distributed to each building so that the message transmission service requested by the IoT sensor can be carried out [Fig 7].

\begin{tabular}{|c|c|}
\hline $\begin{array}{c}\text { External Interface Engine } \\
\text { (E-Mail/App/SNS, etc.) }\end{array}$ & $\begin{array}{c}\text { UI View } \\
\text { (Html5) }\end{array}$ \\
\cline { 2 - 2 } $\begin{array}{c}\text { IoT Sensor Data Transmission Engine } \\
\text { (TCP/IP) }\end{array}$ & $\begin{array}{c}\text { UI Data Push Engine } \\
\text { (Web socket) }\end{array}$ \\
\hline
\end{tabular}


Park1 \& Choi / Journal of System and Management Sciences Vol. 9 (2019) No.3, 45-64

\begin{tabular}{|c|c|}
\hline $\begin{array}{c}\text { Schedule(Task) Engine } \\
\text { (Reguar/Nonnomal Task progress) }\end{array}$ & $\begin{array}{c}\text { Business service } \\
\text { (Plain Old Java Object class) }\end{array}$ \\
\hline $\begin{array}{c}\text { Statistic/Intelligent Judgment Algorithm } \\
\text { Engine }\end{array}$ & $\begin{array}{c}\text { Model } \\
\text { (JDBC /JNDI) }\end{array}$ \\
\hline \multicolumn{2}{|c|}{ JVM (JDK 1.7) } \\
\hline \multicolumn{2}{|c|}{ OS (Linux) } \\
\hline
\end{tabular}

Fig. 7: Control server configuration diagram

The seismic controller is first started through the InitServerHandler, and the data/program synchronization between the integrated control server and the control controller is handled through the DataSyncService. Information that is collected from the dece through SensorDecoder is recorded in IoT Property by invoking MainSocket Thread of HIoT Core.

The PropService performs a function of organizing and recording the collected information for each sensor/attribute, and uses the FixedDelayService to read the sensor data collection records and the occurrence records of nearby buildings over the last $20 \mathrm{~s}$ from the memory DB and pass them over to the EdctService.

EdctService performs a three-party judging process for that information every $2 \mathrm{~s}$ and then returns the results [Fig 8]. 


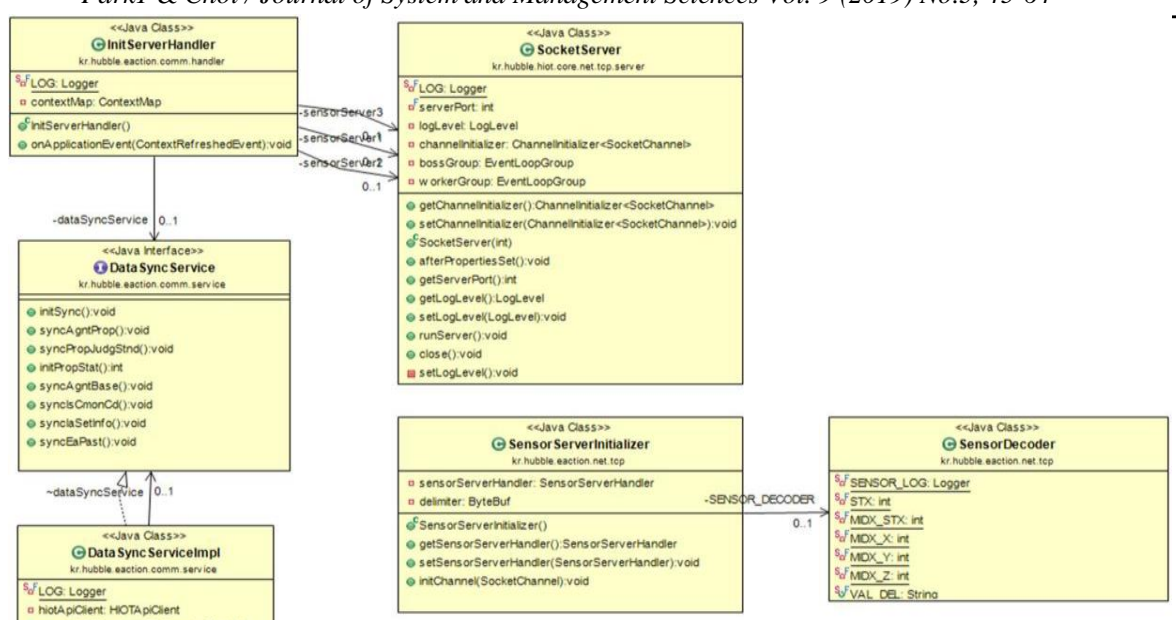

a memorysonsession SalSessionTemplate a casession sasessionTemplate - custive string

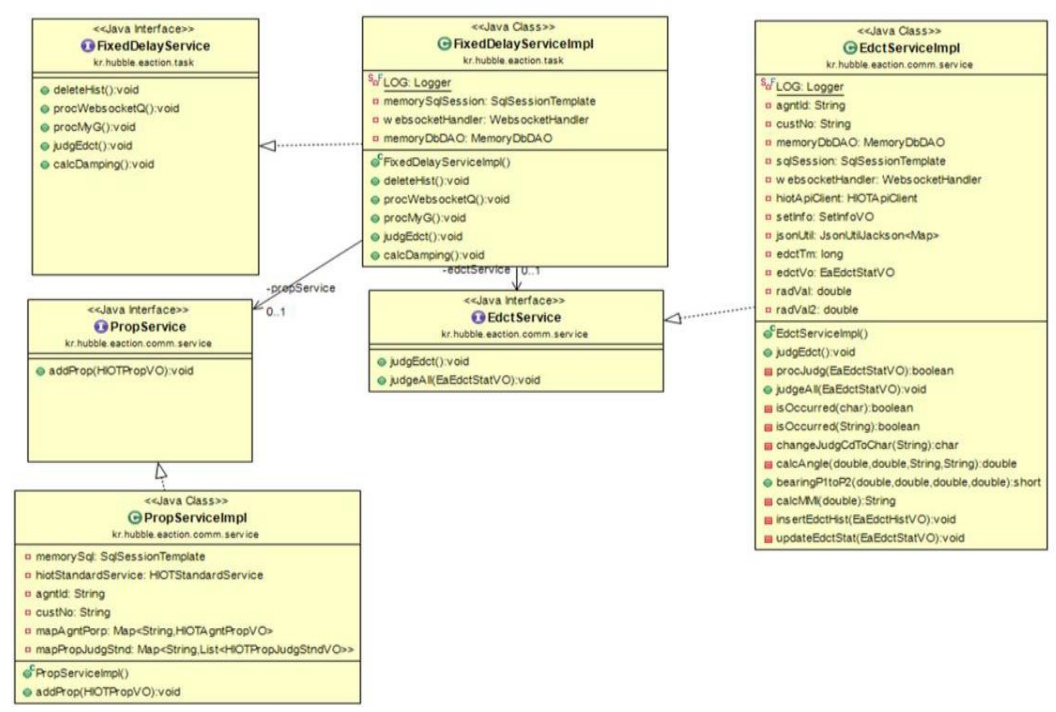

Fig 8: Class design diagram( show partial )

\subsection{Configuration of physical model}

The IA_AGNT_BASE, IA_PROP_STAT, and IA_PROP_HIST tables record and manage the information collected by the sensors and the occurrence of nearby buildings separated by each attribute value. The judgment results for nearby buildings are stored in EA_ABLD_MAP_STAT through the three-party combined judgment algorithm. The results of the determination of consistency with the existing seismic history are stored in EA_PAST, EA_PAST_MAP. 
Details of the entire three-party combined judgment are stored in EA_EDCT_STAT (current state), EA_EDCT_HIST (decision history), and are used to extract the information from the A-Type UI Controller of the EEWS and provide real-time information to the controller UI [Fig 9].

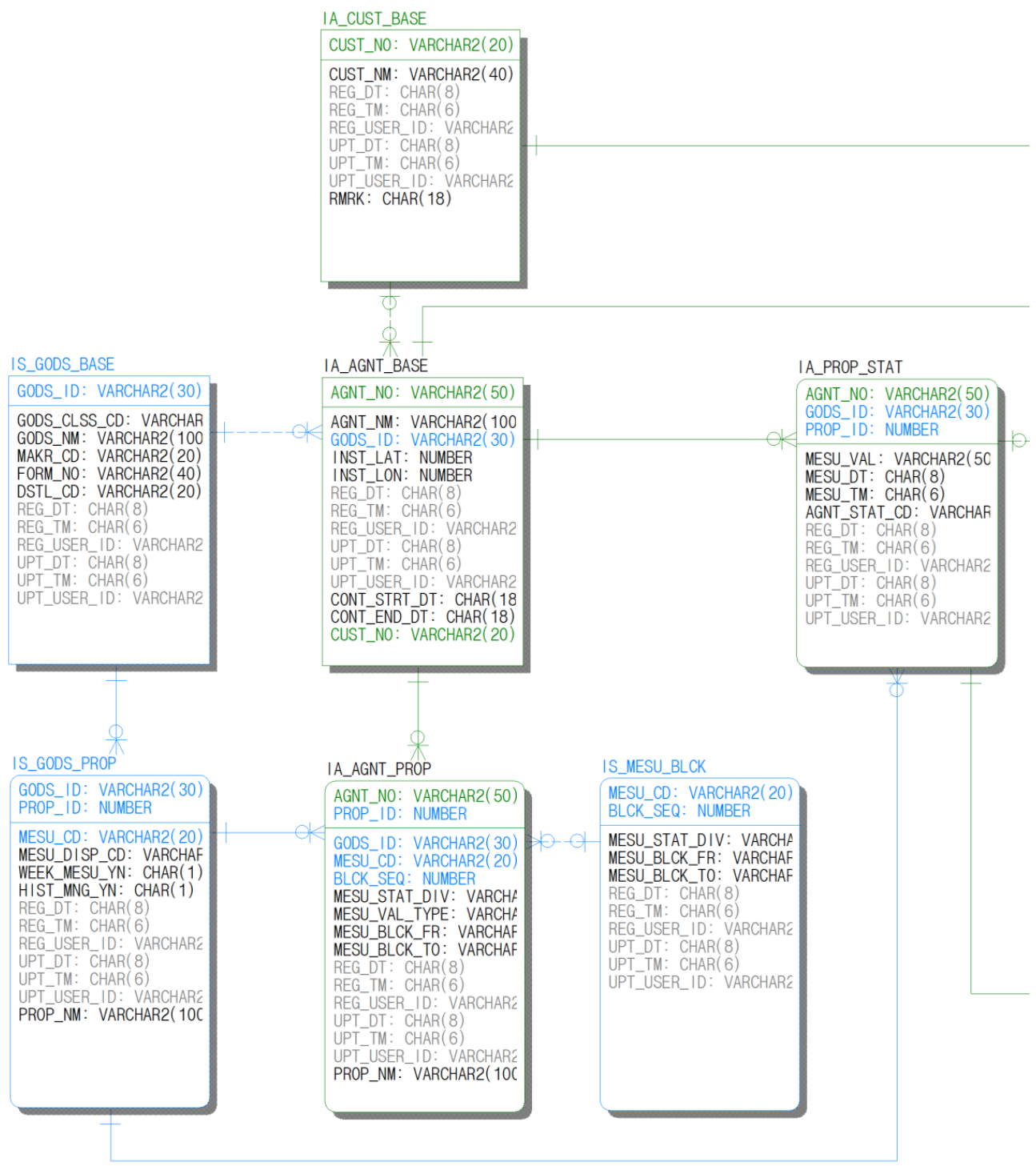




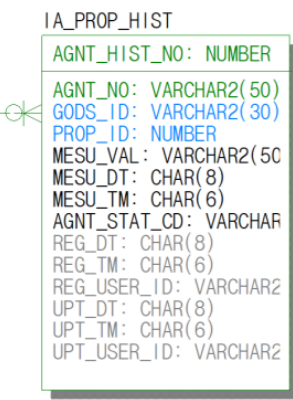

EA_EDCT STAT

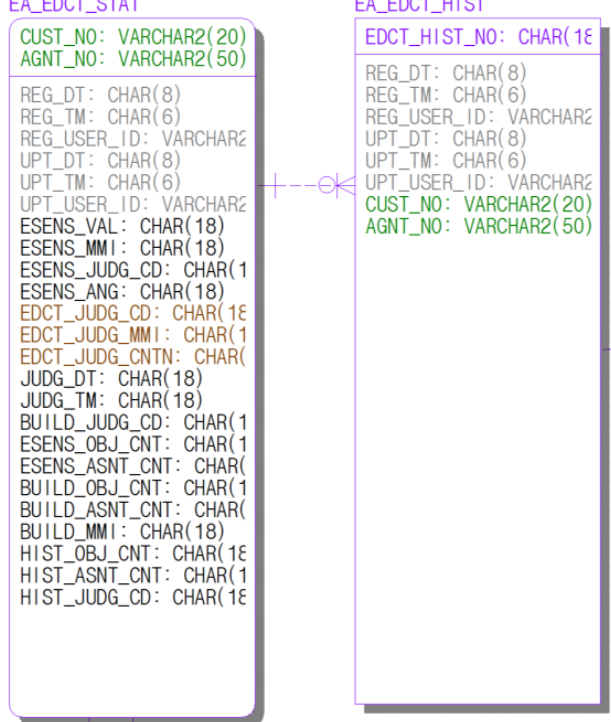

EA_ABLD_MAP_STAT

AGNT_NO: VARCHAR2 $(50)$

GODS_ID: VARCHAR2 30

PROP ID: NUMBER

CUST_NO: VARCHAR2 (20)

REG DT: $C H A R(8)$

REG TM: CHAR (6)

REG USER ID: VARCHABÉ

UPT-DT: CHAR( 8

UPT TM: CHAR ( 6

UPT_USER_ID: VARCHAR'

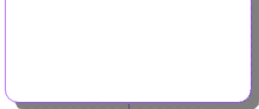

EA_PAST_MAP_STAT

PAST_HIST_NO: CHAR( $1 E$ CUST_NO: VARCHAR2(20) AGNT_NO: VARCHAR2 ( 50$)$

REG_DT: $\operatorname{CHAR}(8)$

REG TM: CHAR (6)

REG USER ID: VARCHARÉ

UPT DT: $\mathrm{CHAR}(8)$

UPT TM: CHAR (6)

UPT_USER_ID: VARCHARÉ

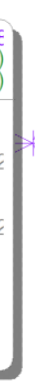

EA_PAST

PAST_HIST_NO: CHAR $(1 \varepsilon$

LAT: NUMBER

LON: NUMBER

REG_DT: $\operatorname{CHAR}(8)$

REG TM: CHAR (6)

REG USER ID: VARCHARE

UPTDT: CHAR (8)

UPT_USER_ID: VARCHARÉ

OCCR_DT: CHAR( 18)

OCCR_DTTM: CHAR (18)

EQKE_SCAL: CHAR( 18

RMRK: $\operatorname{CHAR}(18)$
UPT_TM: CHAR (6)
EA_PAST_MAP_HIST

PAST_HIST_NO: CHAR $(1 \varepsilon$ EDCT_HIST_NO: CHAR $(1 \varepsilon$

REG_DT: $\operatorname{CHAR(~8)}$

REG_TM: CHAR (6)

REG USER ID: VARCHAR'́

UPT_DT: $\operatorname{CHAR}(8)$

UPT TM: CHAR (6)

UPT USER ID: VARCHABÉ

UPT_USER_ID: VARCHARC

EA_ABLD_MAP_HIST

PAST_HIST_NO: CHAR (1E

AGNT_NO: VARCHAR2 $(50)$

GODS_ID: VARCHAR2 (30)

PROP ID: NUMBER

CUST_NO: VARCHAR2 (20)

REG_DT: $\operatorname{CHAR}(8)$

REG TM: CHAR (6)

REG_USER ID: VARCHAR'́

UPT_DT: $\mathrm{CHAR}(8)$

UPT_TM: CHAR(6)

UPT_USER_ID: VARCHARÉ

(1)

Fig 9: Physical data modeling 


\section{Implementation of the proposed EEWS}

\subsection{Hardware implementation}

MEMS-based three-axis acceleration sensor modules were used [8], and seismic sensor equipment and vibration simulation equipment were implemented and tested.
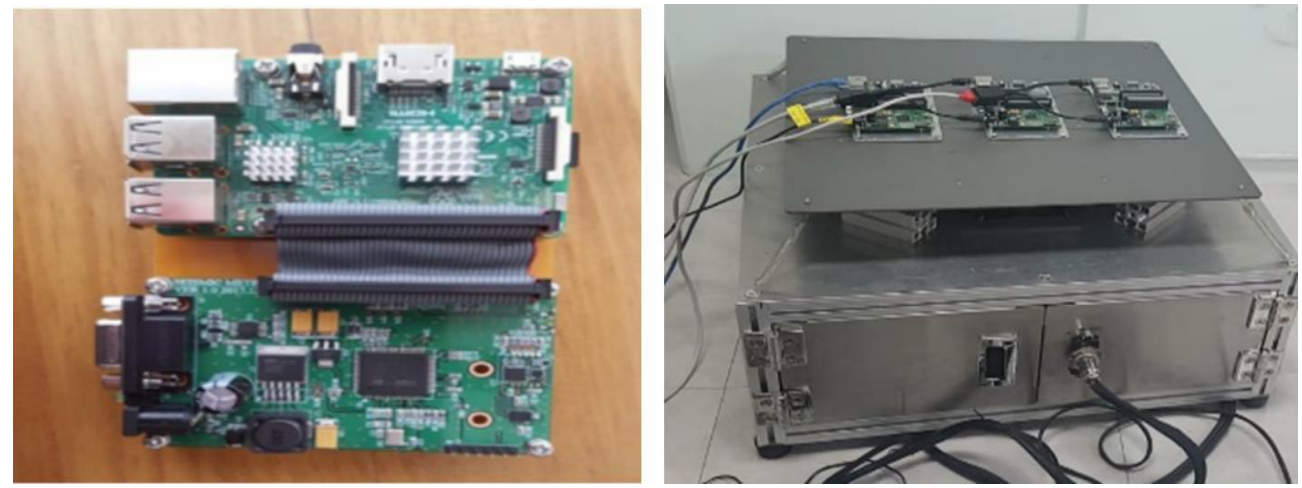

Fig. 10: Vibration simulation and damping sensor unit

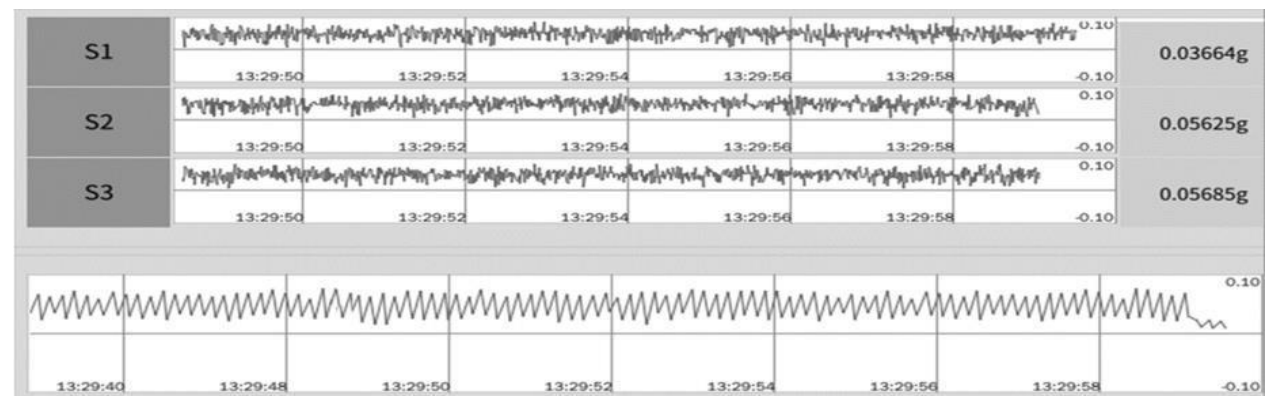

Fig. 11: Vibration simulation

\subsection{Implement of earthquake monitoring software}

This is software which determines whether an earthquake is occurring, detects vibrations, and monitors earthquake certainty. The output of the three-axis acceleration sensors is received sequentially at a high speed, and the sum of this output's vectors is calculated. The system checks whether this value diverges from the initially set warning level. If there is a vibration larger than a magnitude IV on the modified Mercalli scale, a judgment is requested in the earthquake identification module [Table 5]. If waveform patterns from 2 or more places are similar, it is classified as a significant target. If waveform patterns from 3 or more places are similar, it is reported as an earthquake occurrence. 


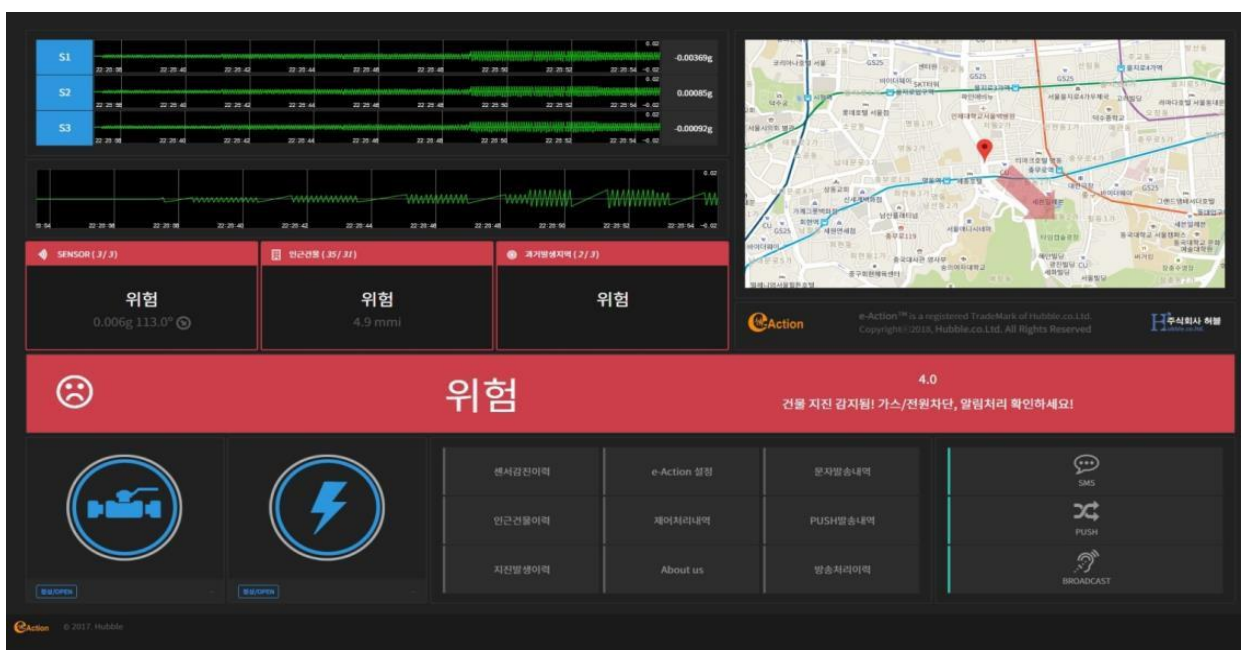

Fig. 12: User interface of earthquake monitoring software of class design diagram

Processing flows which use CallPaths were managed together. To reduce design defects, optimized open source-based class modeling methods were used to implement the earthquake controller. As for the use of the patterned analysis results, accuracy increases as deep learning supervised training format data accumulates; therefore, single-layer perceptron and MLP (multi-layer perceptron) methods were referenced as training methods which use both the training data and the training data's significance when training a neural network. This study used back propagation by adjusting the bonding strength of the neural network training to eliminate the difference between the current output and the expected output.

Table 5: Vibration reaction time test (using vibration simulator)

\begin{tabular}{|c|c|c|c|c|c|c|}
\hline \multicolumn{3}{|c|}{ Test Type } & \multicolumn{4}{|c|}{ Results } \\
\hline $\begin{array}{l}\text { Type- } \\
\text { ID }\end{array}$ & Def. & Goal & Avg.Time & PassCnt & NPassCnt & $\begin{array}{c}\text { SRate } \\
(\%)\end{array}$ \\
\hline TP-101 & Under Min 4 & \multirow{4}{*}{$\begin{array}{l}\text { In } 5.0 \\
\text { Sec }\end{array}$} & $3.71 \mathrm{~s}$ & 475 & 29 & 94.2 \\
\hline TP-102 & Under Min 5 & & $3.49 \mathrm{~s}$ & 497 & 7 & 98.6 \\
\hline TP-103 & Under Min 6 & & $2.41 \mathrm{~s}$ & 503 & 2 & 99.6 \\
\hline TP-104 & Over Min 6 & & $1.06 \mathrm{~s}$ & 500 & 0 & 100.0 \\
\hline
\end{tabular}


Table 6: Test entering virtual data

\begin{tabular}{|c|c|c|c|c|c|c|}
\hline \multicolumn{7}{|c|}{ *Total 630 Counted } \\
\hline \multicolumn{3}{|c|}{ Test Type } & \multicolumn{4}{|c|}{ Results } \\
\hline $\begin{array}{l}\text { Type- } \\
\text { ID }\end{array}$ & Def. & Goal & Avg.Time & PassCnt & NPassCnt & $\begin{array}{c}\text { SRate } \\
(\%)\end{array}$ \\
\hline TP-201 & $\begin{array}{c}\text { Sensor-0, } \\
\text { Bldg-0, H-0 }\end{array}$ & \multirow{7}{*}{$\begin{array}{l}\text { In } 7.0 \\
\text { Sec }\end{array}$} & $4.13 \mathrm{~s}$ & 90 & 0 & 100.0 \\
\hline TP-202 & $\begin{array}{c}\text { Sensor-0, } \\
\text { Bldg-X, H-X }\end{array}$ & & $3.33 \mathrm{~s}$ & 90 & 0 & 100.0 \\
\hline TP-203 & $\begin{array}{c}\text { Sensor-0, } \\
\text { Bldg-0, H-X }\end{array}$ & & $3.61 \mathrm{~s}$ & 90 & 0 & 100.0 \\
\hline TP-204 & $\begin{array}{c}\text { Sensor-0, } \\
\text { Bldg-X, H-0 }\end{array}$ & & $3.18 \mathrm{~s}$ & 90 & 0 & 100.0 \\
\hline TP-205 & $\begin{array}{c}\text { Sensor-X, } \\
\text { Bldg-0, H-0 }\end{array}$ & & $4.31 \mathrm{~s}$ & 83 & 7 & 92.2 \\
\hline TP-206 & $\begin{array}{c}\text { Sensor-X, } \\
\text { Bldg-X, H-0 }\end{array}$ & & $6.65 \mathrm{~s}$ & 47 & 43 & 52.2 \\
\hline TP-207 & $\begin{array}{c}\text { Sensor-X, } \\
\text { Bldg-0, H-X }\end{array}$ & & $4.33 \mathrm{~s}$ & 84 & 6 & 100.0 \\
\hline
\end{tabular}

Large amounts of training data were inputted, and the system was made so that it could judge consistency through similarities in statistical patterning. To increase probability, continuous data accumulation is needed. The pattern recognition rate was used as supplementary data in the three-party combined judgment analysis engine to perform simulations.

\subsection{User earthquake notification app implementation}

An Android app was created, and a simulation was performed at the Korea Polytechnic University Technology Innovation Park. A vibration with a magnitude greater than IV was simulated, and a demonstration was performed in which information on the earthquake epicenter was sent to the user's mobile device as a notification. To confirm the user app response time, the experiment measured the time when the push notification arrived at the user app after the earthquake controller made a judgment. The time at which the transmission target's final case was finished sending was set as the maximum time consumed. The time for sending the notification after the judgment did not exceed a maximum of $1 \mathrm{~s}$, provided that the mobile communications company's network was intact. 


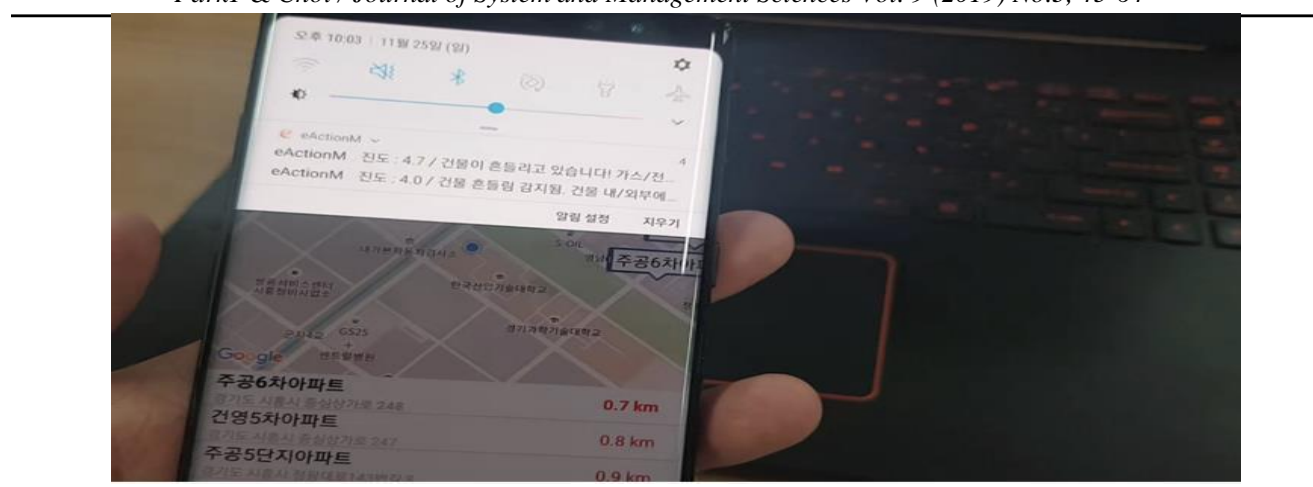

Fig. 13: Seismic monitoring simulation App

Table 7: User APP. response time practical test

\begin{tabular}{|c|c|c|c|c|c|c|}
\hline \multicolumn{3}{|c|}{ Test Type } & \multicolumn{4}{|c|}{ Results } \\
\hline $\begin{array}{l}\text { Type- } \\
\text { ID }\end{array}$ & Def. & Goal & Avg.Time & PassCnt & NPassCnt & $\begin{array}{c}\text { SRate } \\
(\%)\end{array}$ \\
\hline TP-301 & $\begin{array}{l}100 \text { Mag with } \\
\text { DynThreads }\end{array}$ & \multirow{6}{*}{$\begin{array}{c}\text { Receivi } \\
\text { ng Mag } \\
\text { In } \\
\text { 3.0Sec }\end{array}$} & $0.01 \mathrm{~s}$ & 30 & - & 100.0 \\
\hline TP-302 & $\begin{array}{l}200 \text { Mag with } \\
\text { DynThreads }\end{array}$ & & $0.01 \mathrm{~s}$ & 30 & - & 100.0 \\
\hline TP-303 & $\begin{array}{l}500 \text { Mag with } \\
\text { DynThreads }\end{array}$ & & $0.51 \mathrm{~s}$ & 30 & - & 100.0 \\
\hline TP-304 & $\begin{array}{l}700 \text { Mag with } \\
\text { DynThreads }\end{array}$ & & $0.63 \mathrm{~s}$ & 30 & - & 100.0 \\
\hline TP-305 & $\begin{array}{l}\text { 1,000 Mag with } \\
\text { DynThreads }\end{array}$ & & $1.94 \mathrm{~s}$ & 29 & 1 & 96.6 \\
\hline TP-306 & $\begin{array}{l}\text { 2,000 Mag with } \\
\text { DynThreads }\end{array}$ & & $2.87 \mathrm{~s}$ & 28 & 2 & 93.3 \\
\hline
\end{tabular}

\section{Conclusions}

Existing EEWSs usually install seismometers in only one building, and use oneway combined judgment methods to determine earthquakes, which not only makes them less reliable, but can also lead to misjudgment.

Currently, South Korea's EEWS is capable of issuing earthquakes within $25 \mathrm{~s}$ of the initial $\mathrm{P}$ waves observation, and has announced that it will shorten it to within $10 \mathrm{~s}$ by 2020 .

In this paper, to refine the seismic determination method, a patterned seismic identification algorithm called 'three-party combined judgment analysis engine' was proposed, which determines risk and increases accuracy through the comparison of three or more attenuation sensor device information with the vibration condition of nearby buildings, past generation history, and waveform analysis pattern data. 
To verify the algorithms proposed in this paper, it was confirmed that observation of the seismic alarm system is possible within up to $5 \mathrm{~s}$ by applying a hypothetical seismic waveform that could occur at any point in the three-party combined judgment analysis engine. Producing and prototyping the Android app also took no more than $1 \mathrm{~s}$ to inform mobile handsets of seismic information after the judgment of the seismic control roller.

In the future, we need to improve our algorithms through simulation by securing additional seismic data from the special disaster areas in Korea and Asia, which have a history of earthquakes.

If the external network is built in an open environment, designed and implemented to be connected to the national disaster system and broadcasting system, it is expected that the EEWS using the three-party combined judgment analysis engine will be able to transmit and collect the situation to nearby devices, thereby contributing to increasing the speed and reliability of the seismic determination.

\section{Acknowledgement}

This paper is the result of research conducted through the Small and Medium Business Technology Development Support Project (S2492981) which is supported by the Ministry of SMEs and Startups.

\section{References}

Byeung-Leul, L., Seung-Jae, L., Dae-joong, M. \& Jin-woo, J. (2014). Efficiency Test for Low Electric Power Type and MEMS Based 3-axis Accelerometer. Journal of the Korea Institute for Structural Maintenance and Inspection, 18 (1), 160-165.

Centre for Research on the Epidemiology of Disasters (CRED). EM-DAT the international disaster database. (2018). Available from : https://www. cred.be/sites /default/files/CREDNaturalDisaster2018.

Dong-Hoon, S., In-Seub, L., Park, J. \& Heon-Cheol, C. (2012). Earthquake Magnitude Determination using P Phase for Earthquake Early Warning. Journal of the Geological Society of Korea, 48 (1), 101-111.

Eomzi, Y., Ha, S., Kim, W. \& Yun, T. (2018). A Study of the Application of Earthquake Early Warning System for the Enhancements in Protective Action by Korea National Park. 38 (3), 439-448.

Nakamura, Yutaka and Saita, J. (2007). UrEDAS, the Earthquake Warning System: Today and Tomorrow. Earthquake Early Warning Systems, Berlin: Springer, 249281.

Paolo, G., Gaetano, M. \& Jochen, Z. (2007). Earthquake Early Warning Systems. Berlin: Springer.

Peng, C., Chen, Y., Chen, Q., Yung, J., Wang, H., Zhu, X., Xu, Z., Zheng, Y. 
(2017). A New Type of Tri-Axial Accelerometers with High Dynamic Range

MEMS for Earthquake Early Warning. Computer \& Geosciences, 100, 179-187.

Park, Y. S. \& Choi, J. H. (2019). Development of a New Earthquake Early Warning System Based on a Three-Party Combined Judgment Analysis Engine.

International Journal of Urban Design for Ubiquitous Computing, 7(1), 1-6. 